\title{
Perspectives
}

\section{Using Critical Incidents to Understand ESL Student Satisfaction}

John Walker

In a marketized environment, ESL providers, in common with other postcompulsory educational institutions, canvass student satisfaction with their services. While the predominant method is likely to be based on tick-box questionnaires using Likert scales that measure degrees of satisfaction, qualitative methodology is an option when rich data is desired. The well-established Critical Incident Technique (CIT) is particularly useful in this regard as an exploratory methodology with potential to increase knowledge about previously unknown phenomena. A pilot study with a small sample of ESL students was set up to explore ESL student satisfaction using CIT. The data obtained were analyzed within the framework of Johnston's (1995) quality factors, then further categorized in terms of satisfying, dissatisfying, or neutral factors. The findings provided some tentative indications of differentiation among ESL quality factors as perceived by ESL students. Insights were obtained regarding procedural, analytical, and student response issues in the use of CIT in conjunction with satisfaction data. The outcomes supported the view that information obtained through CIT could assist ESL managers and teachers in developing and enhancing quality factors that more accurately reflect student expectations of the service.

Dans un environnement commercialisé, les fournisseurs en ALS, tout comme les autres institutions postsecondaires, sondent les étudiants pour connaitre leur niveau de satisfaction avec les services qu'ils offrent. Alors que la méthode la plus couramment employée repose sur des questionnaires à choix multiples avec des échelles de Likert pour mesurer les niveaux de satisfaction, une méthodologie qualitative est à envisager quand l'on désire des données approfondies. La méthode des incidents critiques (CIT) est bien établie et particulièrement utile à cet égard, étant une méthodologie d'exploration avec le potentiel d'accroitre les connaissances de phénomènes inconnus auparavant. On a mis sur pied une étude pilote avec un petit échantillon d'étudiants en ALS pour explorer, par la CIT, leur niveau de satisfaction. Les données ont été analysées dans le cadre des facteurs de qualité de Johnston (1995) et ensuite catégorisées en fonction de facteurs satisfaisants, insatisfaisants et neutres. Les résultats fournissent des indices de différentiation parmi les facteurs de qualité en ALS, tels que perçus par les étudiants. De nouvelles idées sont ressorties par rapport à l'emploi de la CIT et les enjeux liés à la procédure, l'analyse et les réponses des étudiants dans le contexte de données 
relatives à la satisfaction. La conclusion en est que les informations découlant de la CIT pourraient appuyer les administrateurs et les enseignants dans le développement et l'amélioration des facteurs de qualité de sorte à mieux répondre aux attentes des étudiants en matière des services.

"Service practitioners understand the importance of measuring customer evaluations, such as service quality and customer satisfaction, on a regular basis" (Dabholkar \& Overby, 2005, p. 21). By actively soliciting customer feedback, service operations managers can identify ongoing or potential problems with a view to improving service performance (Pugh, Dietz, Wiley, \& Brooks, 2002). Since many Western postcompulsory educational institutions operate in a context of marketized education, it has likewise become commonplace to canvass student satisfaction with services offered (Riggan, 2012; Thomas \& Cunningham, 2009). Correspondingly, scholarly papers examining various aspects of student satisfaction with postcompulsory educational services have proliferated (e.g., Kuo, Walker, Belland, \& Schroder, 2013; Mark, 2013; Moore, 2011; Serenko, 2011; Sorden \& Munene, 2013; Wood \& Vasquez Urias, 2012). However, this flowering of scholarly interest has not been replicated in the field of English as a Second Language (ESL) because, with only a few exceptions (e.g., Walker, 2010) the theme of ESL student satisfaction with ESL services is absent from the literature. ESL providers undoubtedly survey their students as a matter of course, at least in well-regulated environments, but apart from some publicly funded surveys, information about issues or findings is not normally available in the public domain. As a result, the methods providers use to obtain satisfaction data also remain somewhat obscure. Anecdotally, the staple choice for many institutions will be some form of "tick-box" questionnaire akin to that in the 2006 ELICOS (English Language Intensive Courses for Overseas Students) survey (Australian Education International, 2007), which used a 5-point Likert scale from very dissatisfied to very satisfied to question respondents about specific aspects of their English language study experience. With their standard quantitative design, such instruments undoubtedly represent popular, low-cost options that are efficient to administer and process, as well as being straightforward for users. However, despite their obvious utility, they are subject to the stock criticisms of survey methodology that uses forced-choice formats, for instance, potentially skewed findings resulting from an insufficient range of alternatives, or the inability of respondents to qualify or augment their responses (de Vaus, 2002). Furthermore, survey administrators receive responses only to the items they choose to include in the questionnaire.

For these reasons, qualitative methodologies such as interviews, focus groups, or open-ended questionnaires might present attractive options, taking account, as they do, of the fact that people "ascribe meanings, thoughts, 
and feelings to the situation in which they find themselves," as organizations are "both social systems and the setting for social behaviour" (Maylor \& Blackmon, 2005, p. 220). Indeed, ESL providers may include some qualitative methods in their survey activities despite disincentives, such as the timeconsuming nature of data collection and analysis and the cost involved. These problems notwithstanding, the rich data (Holloway, 1997) obtained from students by way of qualitative survey methods can provide managers and teachers with a clearer and potentially more useful picture of student satisfaction with their institutions than could be obtained by a tick-box survey alone. One such qualitative method is the Critical Incident Technique (CIT). Could this well-established technique be of potential use to ESL managers and teachers in comprehending the nature of student satisfaction with their services?

\section{Conceptual and Theoretical Issues}

\section{Using critical incidents}

A critical incident is "any observable human activity that is sufficiently complete in itself to permit inferences and predictions to be made about the person performing the act," and that has a clear purpose and intent, the consequences of which "are sufficiently definite to leave little doubt concerning its effects" (Flanagan, 1954, p. 327). Because respondents are able to express themselves in their own words and in as detailed a manner as the researcher allows, CIT has the potential to glean rich, concrete, and detailed information on the activity under investigation from the perspective of the participant, thus allowing researchers "to rigorously study a phenomenon and identify issues not previously considered" (Gremler, 2004, p. 69; my emphasis). Simply put, survey participants are asked to recount anecdotes that highlight some aspect(s) of their experiences in a particular context. The resulting data can be content analyzed and classified in order to "provide insights regarding the frequency and patterns of factors that affect the phenomenon of interest" (Gremler, 2004, p. 66).

CIT has been used in a wide range of research fields, in particular services research (e.g., Bitner, Booms, \& Mohr, 1994; Edvardsson, 1992; Hoffman, Kelley, \& Chung, 2003; Holloway \& Beatty, 2008; Johnston, 1995; Mangold, Miller, \& Brockway, 1999). It has also become popular in educational research, for instance, to explore student satisfaction with e-learning (Chen, Lin, \& Kinshuk, 2008), teacher education (Harrison \& Lee, 2011), classroom encounters (Voss, 2009), and student satisfaction with the higher education experience (Douglas, McClelland, \& Davies, 2008). CIT's facility to identify issues unrecognized at the time of the research (Gremler, 2004) represents a major advantage over standard tick-box surveys. Thus, CIT is considered appropriate as an exploratory methodology intended to increase knowledge about previously unknown phenomena (Bitner, Booms, \& Tetreault, 1990), particularly 
in educational service contexts (Douglas, McClelland, Davies, \& Sudbury, 2009). However, CIT does have some obvious drawbacks. In common with other qualitative research methods it may be time-consuming to administer and process, and suffer from a lower response rate than that obtainable from the run-of-the-mill questionnaire. There are issues with respondent recall of incidents (Edvardsson \& Roos, 2001) and problems achieving valid and reliable analysis of the material collected (Vargo, Nagao, He, \& Morgan, 2007).

\section{Service quality and customer satisfaction}

Despite persistent controversies (e.g., Martinez \& Martinez, 2010), the link between perceived service quality and customer satisfaction has been reiterated in the services management/marketing literature (e.g., Carrillat, Jaramillo, \& Mulki, 2009; Grönroos, 2007; Maddern, Maull, Smart, \& Baker, 2007). Thus customers who perceive quality are likely to be satisfied. This conclusion has led researchers to attempt to identify attributes that determine service quality within specific service types (e.g., Aldhizer, Turner, \& Shank, 2002; Kelley \& Turley, 2001; Ramsaran-Fowdar, 2005). If such service quality factors or determinants (Johnston, 1995) can be described and catalogued, the information could assist service managers to focus their efforts, set priorities, and thus improve the efficiency and effectiveness of their service operations. Customer satisfaction is commonly framed within the disconfirmation of expectations (DE) paradigm, namely, an outcome of the comparison customers make between their prepurchase expectations of the service performance and postpurchase perceptions of that performance (Cardozo, 1965; Churchill \& Suprenant, 1982; Oliver, 1980). However, despite its widespread application and relatively strong support in the literature (e.g., Gutek, Groth, \& Cherry, 2002; Szymanski \& Henard, 2001; Yi, 1990), the DE paradigm is limited due to an inability to incorporate some of the complexities involved in the global satisfaction process (Vargo et al., 2007) as consumers may respond differently to different aspects of service provision in terms of variation in degrees of satisfaction, dissatisfaction, or even indifference. Furthermore, "there may well be a difference between the causes of satisfaction and dissatisfaction" (Johnston, 1995, p. 58). Where an estimation of ESL student satisfaction is concerned, this potential for differentiation is further compounded by issues such as ethnicity and cultural influences (Johnson, Herrmann, \& Gustafsson, 2002; Ueltshchy \& Krampf, 2001); language, in terms of accurate respondent comprehension of survey questions, and accuracy of written or verbal responses; and age, in terms of limited knowledge, experience, and maturity about, for example, the validity of teaching methodologies (Szymanski \& Henard, 2001) or expectations of proficiency gain .

In an attempt to respond to such issues, a number of researchers (Cadotte \& Turgeon, 1988; Johnston, 1995; Johnston \& Sylvestro, 1990; Lockwood, 
1994) suggested a refinement of the customer satisfaction process focused on the operation of four service quality factor categories:

1. Hygiene factors (Hygienes or Dissatisfiers) are factors that are likely to cause dissatisfaction if of poor quality or absent, but do not increase satisfaction if they are present or of high quality. They are the basic expectations or requirements of a service from the customer point of view, satisfy extrinsic human needs, and tend to be of a functional and/or instrumental nature (Vargo et al., 2007), but are not likely to be a source of great satisfaction or delight. For instance, students expect to find chairs and desks in their classrooms. The presence of these items does not engender satisfaction, but their absence would likely cause dissatisfaction.

2. Enhancing factors (Enhancers or Satisfiers) are factors that can elicit great satisfaction or delight from customers if they are present, but are unlikely to be grounds for dissatisfaction if they are not. They tend to have the characteristic of "add-ons," signifying augmented features of the service that clients may not necessarily anticipate. An authentic example occurred when ESL staff turned out in the middle of the night to assist students involved in an automobile accident.

3. Critical factors (Criticals) can both delight and dissatisfy clients and, as their name implies, they are key aspects of the service, representing the core features of particular importance to clients (Vargo et al., 2007). These are harder to classify, but previous ESL research (Walker, 2010) identified teaching skills and lesson effectiveness as strong predictors of ESL student satisfaction. Such issues might therefore represent critical factors for ESL students.

4. Neutral factors (Neutrals) are those that have little influence on satisfaction or dissatisfaction. In exploratory focus group research (Walker, 2010), ESL student participants appeared unconcerned about the servicescape (Bitner, 1992) in terms of décor, lighting, or appearance. It may be that these elements were neutral factors for respondents.

The significance of specific service quality factors and/or service features may evolve and change over time, resulting in reassignment to a different category. For instance, satisfiers can become criticals and then hygienes, often in conjunction with technological innovation (Vargo et al., 2007). A good example is broadband access for students. In the early days of the Internet, this was something of a bonus in ESL services. Nowadays, it is a standard feature. Thus it has migrated from an enhancer role to that of a critical or even a hygiene. The utility for service organizations of this approach lies in more efficient and effective priority setting, thus enabling managers to focus on the issues that really matter to customers, while allotting less effort to those that do not. Johnston's (1995) research resulted in the identification of 18 quality factors that could influence customer satisfaction with a service (Appendix 
A). Although not necessarily exhaustive, these factors have constituted a useful basis for further satisfaction studies.

Given its attributes, CIT has been regarded as a suitable choice for research investigating quality and customer/client satisfaction. While there may be overfocus on extremes of satisfaction or dissatisfaction in the data, meaning that many less memorable incidents may not be collected (Strauss \& Weinlich, 1997), CIT allows respondents to narrate first-hand experiences, which researchers can analyze and classify into critical incidents of high and low satisfaction and dissatisfaction. Since the use of CIT for this purpose is expanding into a number of research areas, including education (e.g., Douglas et al., 2008; Voss, 2009), it appears an appropriate vehicle to explore ESL student satisfaction.

\section{A Pilot Study}

Taking these issues into account, a simple pilot study was set up in a university English language centre in order to test the utility of CIT with ESL students. Human ethics clearance was obtained from university authorities. A general invitation was sent out to currently enrolled students to participate in the research, and 23 students accepted. The students were assembled in one group, and the researcher explained the purpose of the research. They were asked to write about two critical incidents that, respectively, made them very pleased/satisfied and very unhappy/dissatisfied with the service they were receiving from the centre, and to explain why they felt that way in each case. The respondents' stories were captured on a paper survey form (Appendix B), which also asked for demographic data. Each critical incident narrated was regarded as one unit of analysis. The data were content analyzed by the researcher, assisted by an independent "judge" in line with Gremler's (2004) recommendations, with the aim of classifying critical incidents within Johnston's (1995) framework of quality factor categories.

\section{Findings and Discussion}

\section{Overview of findings}

The demographic data are shown in Table 1. There was a good gender balance; students were from Asia and the Middle East, and mainly in the age group 21-30. Most students had studied at the centre for five months or less.

Johnston's (1995) quality factors were derived from banking services research. By his own admission, they could probably not be generalized to all service types without augmentation. This was found to be the case in this ESL context, as four themes were identified that did not entirely fit any of Johnston's factors, or appeared to be too important not to designate as discrete factors: 
- Service milieu: This concept refers to the atmosphere, ambience, or mood experienced in a service context, which reflects friendly, efficient, and supportive service (Schneider \& Bowen, 1995).

- Socializing: Douglas et al. (2008) augmented Johnston's (1995) factors with several new categories specific to education, one of which they labelled socializing, that is, the benefit students perceived from making new friends and using student facilities.

- Teaching/learning experience: Given the study context, this theme, unsurprisingly, attracted the most comments.

- Placement/promotion procedure: This encompasses the initial testing and placement of students at an appropriate level of proficiency, as well as promotion to higher levels.

Table 1

Demographics

\begin{tabular}{|c|c|c|c|c|c|}
\hline \multirow[t]{2}{*}{ Gender } & \multicolumn{3}{|c|}{ Female } & \multicolumn{2}{|c|}{ Male } \\
\hline & \multicolumn{3}{|c|}{11} & \multicolumn{2}{|c|}{12} \\
\hline \multirow[t]{2}{*}{ Age } & 20 or & ounger & & & $31-40$ \\
\hline & & 1 & & 21 & 1 \\
\hline \multirow[t]{2}{*}{ Country } & S. Korea & Saudi Arabia & PR China & Thailand & Japan \\
\hline & 10 & 5 & 4 & 2 & 2 \\
\hline \multirow[t]{2}{*}{ Time in Centre } & 1 year & $r$ more & $6-11 \mathrm{mc}$ & & or less \\
\hline & & 4 & & 3 & 16 \\
\hline
\end{tabular}

Content analysis identified a total of 17 quality factors, 13 from Johnston's (1995) list plus the above 4 . A total of 46 positive incidents and 40 negative incidents were recorded and classified (Table 2) according to the augmented list. It can be seen that the most frequently reported incidents were in the teaching/learning experience category (16), followed by communication (9) and flexibility (8). Table 3 provides illustrations of reported incidents for each category identified. Johnston (1995) acknowledged the conspicuous omission of cost of the service from his list, commenting that price might be of major importance for customers in some service types. It is therefore of interest that a mere three incidents concerned study fees, of which only one actually criticized the cost of the service in relation to its perceived quality. 
Table 2

Summary of Positive and Negative Incidents

\begin{tabular}{|c|c|c|}
\hline Quality Factor & Positive & Negative \\
\hline Access & 2 & 1 \\
\hline Attentiveness/helpfulness & 4 & 2 \\
\hline Availability & 0 & 2 \\
\hline Care & 2 & 0 \\
\hline Commitment & 4 & 0 \\
\hline Communication & 5 & 4 \\
\hline Courtesy & 1 & 4 \\
\hline Flexibility & 6 & 2 \\
\hline Friendliness & 4 & 0 \\
\hline Functionality & 0 & 4 \\
\hline Placement/promotion procedures ${ }^{*}$ & 2 & 4 \\
\hline Reliability & 0 & 2 \\
\hline Responsiveness & 1 & 3 \\
\hline Security & 2 & 0 \\
\hline Service milieu* & 4 & 0 \\
\hline Socializing* & 5 & 0 \\
\hline Teaching/learning experience* & 4 & 12 \\
\hline Total & 46 & 40 \\
\hline
\end{tabular}

${ }^{*}=$ Additional quality factor

\section{Table 3}

Quality Factors: Illustrative Positive and Negative Incidents

Category Incident

Access

(+) Student enjoyed using the free bus service.

(-) Student had problems finding a car park at the centre.

Attentiveness/

helpfulness

(+) Staff were helpful and gave advice during admission procedures.

(-) Student got no assistance to book a flight home.

Availability

(-) Student observed students in another group going on weekend activity, but she was not offered this service.

(continued next page) 
Care

Commitment

Communication

Courtesy

Flexibility

Friendliness

Functionality

Placement/promotion procedures*

Reliability

Responsiveness

Security

Service milieu*

Socializing *

Teaching/learning experience*
(+) Student experienced kindness and caring attitude from teachers when having personal problems.

(+) Staff learned and remembered the student's name.

(+) Staff kept student informed about events at the centre.

(-) No one took the time to explain the course of study to the student or how it would be assessed.

(+) Staff treated student respectfully and politely when she requested assistance.

(-) Student felt he and his country were insulted when staff member praised the hard work of students from another country.

(+) Staff member helped student make appointment for medical problem and took student to hospital.

(-) Student was unable to get fee refund when she had to return home early.

(+) Coordinators were friendly and smiling on student arrival at centre.

(-) Student found a poor choice of food at the cafeteria.

(+) When promoted to a higher class, student found interesting new topics, activities, and challenges.

(-) Student was moved to a new class without consultation or explanation.

(-) Student was given incorrect information about fees in home country, and had to pay extra fees on arrival in NZ.

(+) Teachers were willing to answer questions from students in and out of class.

(-) Management asked students for feedback but did not act on it.

(+) Student was given a contact phone number to use in emergencies.

(+) Student found he could learn more effectively because of the positive atmosphere in the centre.

(+) Student enjoyed opportunity to socialize with students from other countries and speak English.

(+) Student enjoyed a particular lesson because teacher used music in class.

(-) In his class, student found too much time devoted to grammar, and not enough to speaking and listening.

${ }^{*}=$ Additional quality factor 


\section{Attempting to classify quality factors}

Once the incidents had been matched with quality factors, an attempt was made to classify them according to the four service quality factor categories (Table 4) as Lockwood (1994) advised:

- Neutrals: Themes that attracted low scores for both positive and negative incidents.

- Hygienes: Themes that have a high score for negative incidents and a low score for positive incidents, since these incidents attract a lot of complaints when they go wrong, but not many comments when they go right (Lockwood, 1994).

- Enhancers: Themes that have a high score for positive incidents but a low score for negative incidents. They potentially delight customers, but are not negatively commented on if they do not occur.

- Criticals: Themes that have a high score in terms of both positive and negative incidents. They "will tend to result in plaudits if everything goes right but brickbats if things go wrong" (Lockwood, 1994, p. 78).

Table 4

Tentative Classification of Quality Factors for ESL Service

\begin{tabular}{lll}
\hline High & HYGIENES & CRITICALS \\
& $\begin{array}{l}\text { Teaching/learning experience } \\
\text { Functionality }\end{array}$ & $\begin{array}{l}\text { Communication } \\
\text { Courtesy? } \\
\text { Placement/promotion procedures? }\end{array}$ \\
& Responsiveness? & \\
Potential & NEUTRALS & \\
to Dissatisfy & Access? & \\
& Care? & ENHANCERS \\
& Security? & Friendliness \\
& Availability? & Commitment \\
& Reliability? & Service milieu \\
& & Socializing \\
& & Flexibility?
\end{tabular}

Low

Low

Potential to Delight

High

The question of what "high" and "low" scores are is unclear, although Lockwood's (1994) advice was to use the Pareto Principle (i.e., 80-20 rule). Given the limited nature of the data collected from this small sample of students, it was not possible to assign all of these themes with anything near $100 \%$ confidence, but a tentative attempt at classification was made (Table 
4). A glance at Table 2 would indicate that the enhancers could probably be most confidently identified, as no negative incidents were reported, and the positive scores are respectable (commitment, friendliness, service milieu, and socializing). The disparity in scores for flexibility might mandate allocating this factor to the enhancers also. The situation with care and security is not so clear, but with their low scores they might belong to the neutrals, along with access, availability, and reliability. With its strongly negative score, teaching/learning experience would appear to be a hygiene factor, along with functionality, and although three others might be assigned to this group-courtesy, placement/ promotion procedures, and responsiveness - question marks would have to be placed against them. The criticals group is, likewise, hard to identify with certainty. On balance, it would appear that communication is a critical, and attentiveness/helpfulness might belong here, but it might also be an enhancer.

Several of Johnston's factors could not be assigned, namely aesthetics, cleanliness/tidiness, comfort, competence, and integrity. The omission of competence might appear strange in an educational context. However, only about three incidents clearly referred to staff or teacher competence-for instance, one where the teaching was of a high standard and another that criticized lack of teacher knowledge of requirements for university study. Incidents that referred to, for example, teachers using handouts instead of textbooks or not focusing on academic English, appeared to relate more to functionality (perhaps organizational or curriculum issues) than competence. After some discussion, therefore, it was felt that the teaching/learning experience factor was too pertinent to ESL to be deconstructed, so for the purpose of this exercise it can be assumed that this factor subsumes some other factors from Johnston's (1995) list. Furthermore, there may be a temptation to assign missing factors to the neutrals category - that is, they are unimportant because they were not "mentioned." However, given the nature of this study, the sample size, and the variation in customer experience, it would dangerous to make this assumption (Johnston \& Heineke, 1998). Even with a respectable sample size and a large number of reported incidents, caution would be advised in claiming generalizability for such a classification, unless some common ground could be established based on findings across a number of institutions, or unless studies could be replicated in different contexts and jurisdictions.

\section{Student response issues}

Quality of narratives: The written student narratives were in some cases not detailed enough to permit accurate analysis and categorization, and the task instructions were, in retrospect, deemed to be too vague. Future versions of the questionnaire should heed Flanagan's (1954) advice about collecting critical incidents, in particular providing a more carefully structured questionnaire, containing more questions and clearer language. For instance, instead of merely asking students to "describe the situation," it would probably pay 
to be more specific-for example, "describe exactly what happened" - and include fields for respondents to report when exactly the incident occurred, who was involved, and so on.

Number of incidents: The questionnaire requested only two critical incidents from students, one positive and one negative. In fact, most respondents obligingly provided more than two incidents. The more incidents collected, the richer and more valuable the data are likely to be. A further redesign of the questionnaire is therefore indicated to offer respondents the option of narrating multiple incidents.

Response language: Although students were given the opportunity to respond in their own language, only one student did this. This majority choice to use English was helpful in some respects, but it was apparent from some of the responses that students were struggling to describe the incidents precisely, and the quality of the data probably suffered as a result. Ideally, students at lower proficiency levels should be encouraged to respond in their own languages, potentially costly and more complex data analysis notwithstanding.

Unintended consequences: The extent and depth of the responses varied immensely, from a couple of lines to, in several instances, an entire page. The researcher sensed an eagerness on the part of a number of respondents to express their opinions, which in some cases revealed strong emotions. An unintended consequence of the exercise for some participants, therefore, may have been the therapeutic effect of putting their views on paper. This insight lends further support to the rationale for carrying out some form of qualitative research, be it CIT or not, with ESL students.

\section{CONCLUSIONS}

This article offered a brief report on the CIT option for canvassing student satisfaction in conjunction with Johnston's (1995) differentiated quality factors, and on some practical and theoretical aspects of designing and administering a CIT study for ESL. As is apparent from the above, the use of CIT for this purpose is not without its problems and controversies. Despite the extra investment in time and effort that CIT surveys imply, however, the major outcome for ESL teachers and managers could be some assurance around which service issues matter to students and which do not. Armed with fresh insights, managers could prioritize more accurately, allocating resources more efficiently and effectively, rather than misdirecting their efforts toward quality factors that are, in fact, insignificant in student terms. It is self-evident, for instance, that hygienes and criticals should attract more managerial attention than neutrals. At the same time, overreliance on enhancers to generate satisfaction, while neglecting hygienes and/or criticals, could result, on balance, in dissatisfied students. It is not suggested that ESL managers abandon their current conventional tick-box surveys (assuming that is what they are using). 
Rather, CIT could be used to complement these on a long-term basis, say once a year, possibly in conjunction with staff professional development activities. This would allow for hitherto unknown issues to be identified as they arise, as the ESL operation grows and matures and as the student population evolves. Over time, managers and teachers could build up an invaluable database of incidents, which could further inform research and practice, for instance by identifying further quality factors specific to ESL. The option of collaborating with a university researcher on such a project would constitute a pragmatic application of Mode 2 Research (Tranfield, 2002), because a major CIT study of ESL student satisfaction would not only assist and inform the organization concerned, but would also make a major contribution to the field. Researchers contemplating this would be advised to consult Gremler's (2004) invaluable paper for advice on how to proceed.

\section{The Author}

John Walker has taught English and managed language programs in various locations around the world. He currently lectures in the School of Management, Massey University, New Zealand. His research interests include service operations management and TESL management in commercial contexts.

\section{References}

Aldhizer, G. R., Turner, L. D., \& Shank, M. D. (2002). Determinants of consulting service quality for accounting and non-accounting service providers. Journal of Information Systems, 16(1), 61-74.

Australian Education International. (2007). 2006 international student survey: English language intensive courses for overseas students [Summary report]. Retrieved from https://internationaleducation.gov.au/research/Publications/Documents/ISS_2006_ELICOS.pdf

Bitner, M. J. (1992). Servicescapes: The impact of physical surroundings on customers and employees. Journal of Marketing, 56(2), 57-71.

Bitner, M. J., Booms, B. H., \& Mohr, L. A. (1994). Critical service encounters: The employee's viewpoint. Journal of Marketing, 58(4), 95-106.

Bitner, M. J., Booms, B. H., \& Tetreault, M. S. (1990). The service encounter: Diagnosing favorable and unfavorable incidents. Journal of Marketing, 54(1), 71-84.

Cadotte, E. R., \& Turgeon, N. (1988). Dissatisfiers and satisfiers: Suggestions from consumer complaints and compliments. Journal of Consumer Satisfaction, Dissatisfaction and Complaining Behaviour, 1, 74-79.

Cardozo, R. N. (1965). An experimental study of customer effort, expectation, and satisfaction. Journal of Marketing Research, 2(3), 244-249.

Carrillat, F. A., Jaramillo, F., \& Mulki, J. P. (2009). Examining the impact of service quality: A meta-analysis of empirical evidence. Journal of Marketing Theory and Practice, 17(2), 95-110.

Chen, N.-S., Lin, K.-M., \& Kinshuk. (2008). Analysing users' satisfaction with e-learning using a negative critical incidents approach. Innovations in Education and Teaching International, $45(2), 115-126$.

Churchill, G. A., \& Suprenant, C. (1982). An investigation into the determinants of customer satisfaction. Journal of Marketing Research, 19(4), 491-504.

Dabholkar, P. A., \& Overby, J. W. (2005). Linking process and outcome to service quality and customer satisfaction evaluations: An investigation of real estate agent service. International Journal of Service Industry Management, 16(1), 10-27.

de Vaus, D. A. (2002). Surveys in social research (5th ed.). Crows Nest, Australia: Allen and Unwin. 
Douglas, J. A., McClelland, R., \& Davies, J. (2008). The development of a conceptual model of student satisfaction with their experience in higher education. Quality Assurance in Education, 16(1), 19-35.

Douglas, J. A., McClelland, R., Davies, J., \& Sudbury, L. (2009). Using critical incident technique (CIT) to capture the voice of the student. TQM Journal, 21(4), 305-318.

Edvardsson, B. (1992). Service breakdowns: A study of critical incidents in an airline. International Journal of Service Industry Management, 3(4), 17-29.

Edvardsson, B., \& Roos, I. (2001). Critical incident techniques: Towards a framework for analysing the criticality of critical incidents. International Journal of Service Industry Management, 12(3), 251-268.

Flanagan, J. C. (1954). The critical incident technique. Psychological Bulletin, 51(4), 327-358.

Gremler, D. D. (2004). The critical incident technique in service research. Journal of Service Research, 7(1), 65-89.

Grönroos, C. (2007). Service management and marketing: Customer management in service competition. Chichester, UK: John Wiley \& Sons.

Gutek, B. A., Groth, M. A., \& Cherry, B. (2002). Achieving service success through relationships and enhanced encounters. Academy of Management Executive, 16(4), 132-144.

Harrison, J. K., \& Lee, R. (2011). Exploring the use of critical incident analysis and the professional learning conversation in an initial teacher education programme. Journal of Education for Teaching: International Research and Pedagogy, 37(2), 199-217.

Hoffman, K. D., Kelley, S. W., \& Chung, B. C. (2003). A CIT investigation of servicescape failures and associated recovery strategies. Journal of Services Marketing, 17(4), 322-340.

Holloway, B. B., \& Beatty, S. E. (2008). Satisfiers and dissatisfiers in the online environment: A critical incident assessment. Journal of Service Research, 10(4), 347-364.

Holloway, I. (1997). Basic concepts for qualitative research. Oxford, UK: Wiley-Blackwell.

Johnson, M. D., Herrmann, A., \& Gustafsson, A. (2002). Comparing customer satisfaction across industries and countries. Journal of Economic Psychology, 23(6), 749-770.

Johnston, R. (1995). The determinants of service quality: Satisfiers and dissatisfiers. International Journal of Service Industry Management, 6(5), 53-71.

Johnston, R., \& Heineke, J. (1998). Exploring the relationship between perception and performance: Priorities for action. Service Industries Journal, 18(1), 101-112.

Johnston, R., \& Silvestro, R. (1990, November). The determinants of service quality: A customerbased approach. Proceedings of the Decision Science Institute Conference. San Diego, CA: Macmillan Indian.

Kelley, S. W., \& Turley, L. W. (2001). Consumer perceptions of service quality attributes at sporting events. Journal of Business Research, 54(2), 161-166.

Kuo, Y.-C., Walker, A. E., Belland, B. R., \& Schroder, K. E. E. (2013). A predictive study of student satisfaction in online education programs. International Review of Research in Open and Distributed Learning, 14(1), 16-39.

Lockwood, A. (1994). Using service incidents to identify quality improvement points. International Journal of Contemporary Hospitality Management, 6(1/2), 75-80.

Maddern, H., Maull, R., Smart, A., \& Baker, P. (2007). Customer satisfaction and service quality in UK financial services. International Journal of Operations and Production Management, 27(9), 998-1019.

Mangold, W. G., Miller, F., \& Brockway, G. R. (1999). Word-of-mouth communication in the service marketplace. Journal of Services Marketing, 13(1), 73-89.

Mark, E. (2013). Student satisfaction and the customer focus in higher education. Journal of Higher Education Policy and Management, 35(1), 2-10.

Martinez, J. A., \& Martinez, L. (2010). Some insights on conceptualizing and measuring service quality. Journal of Retailing and Consumer Services, 17(1), 29-42.

Maylor, H., \& Blackmon, K. (2005). Researching business and management: A roadmap for success. Basingstoke, UK: Palgrave Macmillan. 
Moore, M. M. (2011). Student satisfaction and graduate part-time students. Continuing Higher Education Review, 75, 113-120.

Oliver, R. L. (1980). A cognitive model of the antecedents and consequences of satisfaction decisions. Journal of Marketing Research, 17(4), 460-469.

Pugh, S. D., Dietz, J., Wiley, J. W., \& Brooks, S. M. (2002). Driving service effectiveness through employee-customer linkages. Academy of Management Executive, 16(4), 73-84.

Ramsaran-Fowdar, R. R. (2005). Identifying health care quality attributes. Journal of Health and Human Services Administration, 27(4), 428-443.

Riggan, M. (2012). Between efficiency and effectiveness: Evaluation in for-profit education organizations. Washington, DC: American Enterprise Institute.

Schneider, B., \& Bowen, D. E. (1995). Winning the service game. Boston, MA: Harvard Business School Press.

Serenko, A. (2011). Student satisfaction with Canadian music programmes: The application of the American customer satisfaction model in higher education. Assessment and Evaluation in Higher Education, 36(3), 281-299.

Sorden, S. D., \& Munene, I. I. (2013). Constructs related to community college student satisfaction in blended learning. Journal of Information Technology Education: Research, 12, 251-270.

Strauss, B., \& Weinlich, B. (1997). Process-oriented measurement of service quality: Applying the sequential incident technique. European Journal of Marketing, 31(1), 33-55.

Szymanski, D. M., \& Henard, D. H. (2001). Customer satisfaction: A meta-analysis of the empirical evidence. Journal of the Academy of Marketing Science, 29(1), 16-35.

Thomas, J. L., \& Cunningham, B. J. (2009). Clients' satisfaction with monopolistic services and commitment to the organization: A university context. Journal of Marketing for Higher Education, 19(2), 179-190.

Tranfield, D. (2002). Formulating the nature of management research. European Management Journal, 20(4), 378-382.

Ueltschy, L. C., \& Krampf, R. F. (2001). Cultural sensitivity to satisfaction and service quality measures. Journal of Marketing Theory and Practice, 9(3), 14-31.

Vargo, S. L., Nagao, K., He, Y., \& Morgan, F. W. (2007). Satisfiers, dissatisfiers, criticals, and neutrals: A review of their relative effects on customer (dis)satisfaction. Academy of Marketing Science Review, 11(2), 1-19.

Voss, R. (2009). Studying critical classroom encounters: The experiences of students in German college education. Quality Assurance in Education, 17(2), 156-173.

Walker, J. (2010). Service, satisfaction and climate: Perspectives on management in English language teaching. Bingley, UK: Emerald.

Wood, J. L., \& Vasquez Urias, M. C. (2012). Community college versus proprietary college outcomes: Student satisfaction among minority males. Community College Enterprise, 18(2), $83-100$.

Yi, Y. (1990). A critical review of consumer satisfaction. In V. A Zeithaml (Ed.), Review of marketing, 1990 (pp. 68-123). Chicago, IL: American Marketing Association. 


\section{Appendix A \\ Definitions of the 18 Determinants of Service Quality (Johnston, 1995)}

Access: The physical approachability of service location, including the ease of finding one's way around the service environment and the clarity of route.

Aesthetics: Extent to which the components of the service package are agreeable or pleasing to the customer, including both the appearance and the ambience of the service environment, the appearance and presentation of service facilities, goods, and staff.

Attentiveness/helpfulness: The extent to which the service, particularly of contact staff, either provides help to the customer or gives the impression of interest in the customer and shows a willingness to serve.

Availability: The availability of service facilities, staff, and goods to the customer. In the case of contact staff, this means both the staff/customer ratio and the amount of time each staff member has available to spend with each customer. In the case of service goods, availability includes both the quantity and the range of products made available to the customer.

Care: The concern, consideration, sympathy, and patience shown to the customer. This includes the extent to which the customer is put at ease by the service and made to feel emotionally (rather than physically) comfortable.

Cleanliness/tidiness: The cleanliness and the neat and tidy appearance of the tangible components of the service package, including the service environment, facilities, goods, and contact staff.

Comfort: The physical comfort of the service environment and facilities.

Commitment: Staff's apparent commitment to their work, including the pride and satisfaction they apparently take in their job, their diligence, and thoroughness.

Communication: The ability of the service providers to communicate with the customer in a way he or she will understand. This includes the clarity, completeness, and accuracy of both verbal and written information communicated to the customer and the ability of staff to listen to and understand the customer.

Competence: The skill, expertise, and professionalism with which the service is executed. This includes the carrying out of correct procedures, correct execution of customer instructions, degree of product or service knowledge exhibited by contact staff, the rendering of good, sound advice, and the general ability to do a good job.

Courtesy: The politeness, respect, and propriety shown by the service, usually contact staff, in dealing with the customer and his or her property. This includes the ability of staff to be unobtrusive and uninterfering when appropriate. 
Flexibility: A willingness and ability on the part of the service worker to amend or alter the nature of the service or product to meet the needs of the customer.

Friendliness: The warmth and personal approachability (rather than physical approachability) of the service providers, particularly of contact staff, including cheerful attitude and the ability to make the customer feel welcome.

Functionality: The serviceability and fitness for purpose or "product quality" of service facilities and goods.

Integrity: The honesty, justice, fairness, and trust with which customers are treated by the service organization.

Reliability: The reliability and consistency of performance of service facilities, goods, and staff. This includes punctual service delivery and an ability to keep to agreements made with the customer.

Responsiveness: Speed and timeliness of service delivery. This includes the speed of throughput and the ability of the service providers to respond promptly to customer requests, with minimal waiting and queuing time. Security: Personal safety of the customer and his or her possessions while participating in or benefiting from the service process. This includes the maintenance of confidentiality.

\section{Appendix B \\ Questionnaire Used in Pilot Study}

Please think about your overall experience as a student at this English language centre. Think about all the services included in the study package you have paid for. Consider anything to do with the service that is important to you personally. You can write your answer in English, or in your own language, if you prefer.

\section{Question 1}

- Think of a time when you felt very pleased and satisfied with the service you received from this English language centre.

- Describe the situation:

- Explain why you felt so pleased/satisfied:

\section{Question 2}

- Think of a time when you felt very unhappy and dissatisfied with the service you received from this English language centre.

- Describe the situation:

- Explain why you felt so unhappy/dissatisfied: 